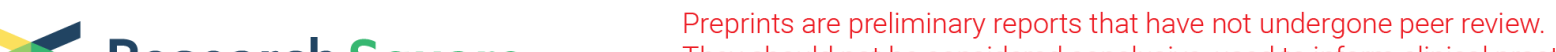 $\begin{array}{ll}\text { Research Square } & \text { They should not be considered conclusive, used to inform clinical practice, } \\ \text { or referenced by the media as validated information. }\end{array}$
}

\section{High-Entropy-Stabilized Polyanionic Cathodes with Multiple Redox Reactions for Sodium-Ion Battery Applications}

\section{Huangxu Li}

City University of Hong Kong

Ming Xu ( $\sim$ xuming@xjtu.edu.cn)

Xi'an Jiaotong University https://orcid.org/0000-0002-1457-9469

Huiwu Long

City University of Hong Kong

Jingqiang Zheng

Central South University

Kuo Yuan

City University of Hong Kong

Liuyun Zhang

Central South University

YangYang Xie

Central South University

Shihao Li

Central South University

Jun Gao

Central South University

Yanqing Lai

Central South University

\section{Zhian Zhang}

Central South University https://orcid.org/0000-0002-8691-6006

\section{Article}

Keywords: High-entropy, Polyanionic materials, Multiple redox reactions, Cathode materials, Sodium-ion battery

Posted Date: January 5th, 2022

DOI: https://doi.org/10.21203/rs.3.rs-1186975/v1 
License: (c) (i) This work is licensed under a Creative Commons Attribution 4.0 International License. Read Full License 


\section{Abstract}

High-entropy (HE) materials containing multiple elements have created a growing interest in exploring the property limits of electrodes in energy storage and understanding the underlying chemical/physical mechanisms. Here, we show a substantial improvement in performance of HE-based cathodes in sodiumion batteries (SIBs). Polyanionic structure has a large compositional flexibility and can incorporate many active transition-metal (TM) species, which is an ideal platform to design HE cathode materials. As a proof of concept, we show that HE sodium superionic conductor (HE-NASICON) materials can be synthesized via a facile sol-gel method. By comparing a group of HE-NASICON cathodes containing different contents of TM species, we demonstrate that the multi-Na-ions intercalation/deintercalation process is highly reversible, whereas capacity and cycling stability are improved. The HE-NASICON cathode with equal molarity of five TM species achieves a high capacity of $161 \mathrm{~mA} \mathrm{~h} \mathrm{~g}^{-1}$ and capacity retention of $85 \%$ when cycling at a high rate of 5 C over 1000 cycles. In-situ XRD and spherical-aberrationcorrected transmission electron microscope (ACTEM) also demonstrate a robust trigonal phase with a volume change of merely $4.07 \%$ during the multi-Na-ions storage. These results reveal the effectiveness of HE concept in expediting high-performance polyanionic cathodes for real SIBs applications.

\section{Introduction}

The quick-emerging paradigm of renewable energy development and use of rechargeable Li-ion batteries on a large scale are being challenged by the scarcity of lithium sources and uneven geographical distribution. ${ }^{1,2,3,4}$ In this context, sodium-ion batteries (SIBs) technology is an attractive option due to low cost, abundant and environmentally friendly sodium resources. Most importantly, it can be easily and rapidly replicated from Li-ion battery technologies regarding industrial and commercial processes. ${ }^{5,6,7,8}$ Major obstacles to using SIBs technology for real applications include the low capacity and unsatisfactory electrochemical stability, which are directly determined by the properties of cathodes in SIBs. Through comparative studies, sodium superionic conductor (NASICON) materials have received considerable interests due to the 3D open framework, structural diversity, and exceptional Na-ion mobilities. ${ }^{9,10}$ Recently, researchers incorporate high-valent redox centers into NASICON materials to ensure multiple electrons transfer and high capacities of cathodes, for example $\mathrm{Na}{ }_{3} \mathrm{VCr}\left(\mathrm{PO}_{4}\right)_{3},{ }^{11}$ $\mathrm{Na}_{4} \mathrm{VMn}_{0.5} \mathrm{Fe}_{0.5}\left(\mathrm{PO}_{4}\right)_{3},{ }^{12}$ and $\mathrm{Na}_{4} \mathrm{MnV}\left(\mathrm{PO}_{4}\right)_{3}{ }^{13,14}$ etc. Nevertheless, multi-Na-ions intercalation/deintercalation process generally causes a series of issues, including large volume change (ca. 9.89\%), high-capacity irreversibility, and irreversible crystal phase evolution (monoclinic $\rightarrow$ rhombohedral) under high voltage operation $\left(>3.8 \mathrm{~V}\right.$ vs. $\left.\mathrm{Na} / \mathrm{Na}^{+}\right)$, which are plaguing the implementation of NASICON cathodes in practical cell. ${ }^{15,16}$ Although all these undesirable performance degradations are named with different terminologies, the general strategy is to improve intrinsic structure stability and manipulate multiple redox reactions to enable highly reversible NASICON cathodes.

High-entropy (HE) alloys have stimulated increasing interest ever since the report of the first example in 2004, mostly ascribed to their high strength and ductility paired with high fracture toughness, fatigue 
resistance, and creep resistance. ${ }^{17,18,19,20}$ The evolved HE oxides, $^{18,21,22,23}$ dichalcogenides, $^{24}$ hexacyanometalates, ${ }^{25}$ etc. also demonstrate unique properties for various applications including catalysis and energy storage. NASICON structure have a large compositional flexibility and can incorporate many active transition-metal (TM) species, such as V, Mn, Cr, Fe, Ti, etc. If the HE concept works in NASICON cathodes, one would expect that increasing the number of TM species would enable multiple redox reactions by preventing the collapse of structure. As a proof of concept, here, we develop a novel HE NASICON material $\mathrm{Na}_{3.4} \mathrm{Fe}_{0.4} \mathrm{Mn}_{0.4} \mathrm{~V}_{0.4} \mathrm{Cr}_{0.4} \mathrm{Ti}_{0.4}\left(\mathrm{PO}_{4}\right)_{3}(\mathrm{HE}-\mathrm{NASICON})$. The multi-active TM species in the polyanionic structure are demonstrated to enable multiple Na-ions storage with robust structural stability. Specifically, we uncover the structure details of these HE materials, and demonstrate a remarkably high capacity of $161.3 \mathrm{~mA} \mathrm{~h} \mathrm{~g}^{-1}\left(1.5 \sim 4.5 \mathrm{~V}\right.$ vs. Na/ Na $\left.{ }^{+}\right)$. In-situ XRD identifies that the multiNa-ions intercalation/deintercalation process of the HE-NASICON materials is highly reversible, accompanying with a volume change of merely $4.07 \%$, which endows the material with good cycling stability. To our best knowledge, this is the very first study of polyanionic cathode materials based on HE concept for applications in batteries, which paves a new way for exploring next-generation SIBS.

\section{Results}

Materials characterizations. Compared to traditional NASICON material with single transition-metal (TM), the HE-NASICON material is designed to have five different TMs (Fe, Mn, V, Ti, Cr) located at the TM sites of the crystal lattice with equal atomic concentration, as schematically illustrated in Fig. 1a. The HENASICON was synthesized by a general sol-gel method followed with a heat-treatment at $700^{\circ} \mathrm{C}$. Rietveld refinement was conducted to analyze X-ray diffraction (XRD) to identify crystal structure of the asprepared material, and the profile is shown in Fig. 1b. The $R_{w p}=2.70 \%$ and $R_{p}=2.15 \%$ indicate the refine results are satisfactory. It reveals that the HE-NASICON adopts a trigonal crystal phase with space group of $R-3 c$, and lattice parameters were determined to be $a=b=8.7158 \AA, c=21.7979 \AA, V=1434.05 \AA^{3}$. No impurity phases were detected, indicating an integrated phase of the HE-NASICON regardless the complexity of its composition. In the analysis of the crystal phase, all of the five TMs (Fe, Mn, V, Ti, Cr) occupy the octahedra site of $12 c$ with equal molarities. While there are two types of $\mathrm{Na}$ that located in the $6 b$ site (Na1) and $18 e$ site (Na2), with an occupancy factor of 0.539 and 0.970 , respectively. Crystal structure of the HE-NASICON is depicted in Fig. 1c, where the $\mathrm{TMO}_{6}$ octahedra and $\mathrm{PO}_{4}$ tetrahedra are corner-shared to construct the 3D framework structure. More information about the refined structure parameters is listed in Table S2. The fingerprint of $\left[\mathrm{PO}_{4}\right]$ group in the HE-NASICON structure was detected by Raman spectra (Fig. S1). The peaks located at $1347.8 \mathrm{~cm}^{-1}$ and $1594.7 \mathrm{~cm}^{-1}$ correspond to the Dband and G-band of carbon material, which derives from the pyrolysis of organic species in the raw materials. ${ }^{26}$ The amount of carbon is around $6.78 \%$, which is measured by thermogravimetry (TG, Fig. S2).

Morphology of the HE-NASICON was disclosed by scanning electron microscopy (SEM). As shown in Fig. S3, the smooth irregular polyhedral shaped particles are displayed with a wide size distribution ranging from nanometer to micrometer scale. Spherical-aberration-corrected transmission electron microscope 
(ACTEM) was further employed to characterize the detailed structure of the material (Fig. 2a-d). An interphase between the amorphous carbon and crystalline HE-NASICON can be seen in Fig. 2b. The lattice of crystalline HE-NASICON was visualized by high-resolution TEM (HR-TEM). The atomic lattice with an interspacing of $6.22 \AA$ should be indexed to the (012) planes of HE-NASICON structure (Fig. 2c). Fig. 2d is the corresponded fast Fourier transform (FFT) patterns, where the (006), (012), (02-2), and (01-4) facets are identified, exhibiting a typical NASICON crystal structure that is coincident with the Rietveld refinement of XRD. For HEMs, the diverse TMs should be distributed evenly in the material to avoid phase/composition segregation. ${ }^{27}$ Energy dispersive spectrometer (EDS) was then used to check the element compositions and distributions of the HE-NASICON. As presented in Fig. S4 and Fig. 2e, the Na, P, $\mathrm{O}, \mathrm{Fe}, \mathrm{Mn}, \mathrm{V}, \mathrm{Ti}, \mathrm{Cr}$ are detected and the atomic ratio of the TMs is almost equal. Besides, the elemental mapping images show uniform distribution of all the elements (Fig. 2f), manifesting that the successful synthesis of the high-entropy $\mathrm{Na}_{3.4} \mathrm{Fe}_{0.4} \mathrm{Mn}_{0.4} \mathrm{~V}_{0.4} \mathrm{Cr}_{0.4} \mathrm{Ti}_{0.4}\left(\mathrm{PO}_{4}\right)_{3}$ material.

Survey spectrum of the X-ray photoelectron spectroscopy (XPS) confirms the existence of $\mathrm{Na}, \mathrm{P}, \mathrm{O}, \mathrm{Fe}, \mathrm{Mn}$, $\mathrm{V}, \mathrm{Ti}$, and $\mathrm{Cr}$ for HE-NASICON (Fig. 2g). The detailed spectra of each TM are also probed to analyze their chemical states (Fig. 2h-I). The characteristic peaks of Fe $2 p$ spectra that located at $711.68 \mathrm{eV}\left(\mathrm{Fe} 2 \mathrm{p}_{3 / 2}\right)$ and $724.18 \mathrm{eV}\left(\mathrm{Fe} \mathrm{2} \mathrm{p}_{1 / 2}\right)$ correspond to $\mathrm{Fe}^{2+}$ species; while the peaks at $715.18 \mathrm{eV}\left(\mathrm{Fe} \mathrm{2} \mathrm{p}_{3 / 2}\right)$ and 727.28 $\mathrm{eV}\left(\mathrm{Fe} 2 \mathrm{p}_{1 / 2}\right)$ correspond to $\mathrm{Fe}^{3+}$ species and the portion is about $39.4 \% .{ }^{28,29}$ For $\mathrm{Mn} 2 \mathrm{p}$, the peaks located at $741.28 \mathrm{eV}\left(\mathrm{Mn} \mathrm{2}_{3 / 2}\right)$ and $753.28 \mathrm{eV}\left(\mathrm{Mn} \mathrm{2}_{1 / 2}\right)$ indicate the 2+ oxidation state of $\mathrm{Mn}^{30,31}$ The peaks at 516.78 and $523.28 \mathrm{eV}$ in the $\mathrm{V} 2 \mathrm{p}$ spectrum can be indexed to the $\mathrm{V}^{3+}$ species. ${ }^{14,32} \mathrm{The}^{\mathrm{Ti}}$ also show mixed states as the Fe does. Specifically, the Ti $2 p_{3 / 2}$ and Ti $2 p_{1 / 2}$ peaks at $458.88 \mathrm{eV}$ and 464.78 $\mathrm{eV}$ should be assigned to the $\mathrm{Ti}^{3+}$ species, while the peaks at $460.28 \mathrm{eV}$ and $466.08 \mathrm{eV}$ imply the $\mathrm{Ti}^{4+}$ species. The $\mathrm{Ti}^{3+}$ is around $33.8 \%{ }^{33,34}$ For the $\mathrm{Cr} 2 \mathrm{p}$ spectrum, it shows two main peaks at $577.98 \mathrm{eV}(\mathrm{Cr}$ $\left.2 p_{3 / 2}\right)$ and $587.58 \mathrm{eV}\left(\mathrm{Cr} 2 \mathrm{p}_{1 / 2}\right)$, respectively, which can be ascribed to the $\mathrm{Cr}^{3+}$ species. ${ }^{31}$ The overall charge state of TMs was calculated to be 5.62 , which is very close to the ideal value of 5.60 in the $\mathrm{Na}_{3.4} \mathrm{Fe}_{0.4} \mathrm{Mn}_{0.4} \mathrm{~V}_{0.4} \mathrm{Cr}_{0.4} \mathrm{Ti}_{0.4}\left(\mathrm{PO}_{4}\right)_{3}$.

Electrochemical properties of the HE-NASICON material in sodium-ion battery. After confirming the successful synthesis of HE-NASICON, electrochemical performance of the material was then studied. The HE-NASICON half-cells were operated in the voltage range between 1.5 and $4.5 \mathrm{~V}\left(\mathrm{vs}\right.$. $\mathrm{Na}^{+} / \mathrm{Na}$ ). As shown in Fig. 3a, the HE-NASICON can deliver a reversible capacity reaching $161.3 \mathrm{~mA} \mathrm{~h} \mathrm{~g}^{-1}$ at $0.1 \mathrm{C}(1 \mathrm{C}=150$ $\mathrm{mA} \mathrm{h} \mathrm{g}^{-1}$ ). The capacity is much larger than the general NASICON materials with 2-sodium storage (>120 $\mathrm{mA} \mathrm{h} \mathrm{g}^{-1}$ ), enabling the HE-NASICON a multi-sodium storage cathode as expected. The charge/discharge profiles exhibit a multi-steps pattern, indicating consecutive redox reactions of multiple active transitionmetals in NASICON structured materials. ${ }^{35}$ Four pairs of redox potentials at 1.69/1.53 V, 2.25/2.21 V, 3.41/3.40 V, and 4.08/4.08 V are found in the dQ/dV plot (Fig. 3b). The small gaps between the oxidation and reduction potential of each redox pair indicate highly reversible sodium storage process with good electrode kinetics. Fig. $3 c$ presents rate performance of the cathode. At the current density of $0.1,0.2,0.5$, $1,2,5,10$, and 20 C, the HE-NASICON exhibits a discharge capacity of 163.0, 138.3, 116.2, 106.4, 99.4, 
87.7, 76.1, and $58.8 \mathrm{~mA} \mathrm{~h} \mathrm{~g}^{-1}$, respectively. When the current returns to $0.5 \mathrm{C}$ from the high-rate of $20 \mathrm{C}$, the discharge capacity can achieve $109 \mathrm{~mA} \mathrm{~h} \mathrm{~g}^{-1}$, implying good reversibility for flexible sodium storage. For multi-sodium storage within a wide voltage window, cyclability is a key issue because the too many sodium-ions insertion/extraction in the lattice can significantly affect structure stability and cause capacity decay. ${ }^{16,35}$ To check the cyclability of multi-sodium storage reaction, the HE-NASICON cathode was operated at $0.5 \mathrm{C}$ for 100 cycles. As displayed in Fig. 3d, a remarkable capacity retention of $93.0 \%$ was achieved. Even at the high-rate of $5 \mathrm{C}$, capacity of the cathode after 1000 cycles still remines $85.3 \%$ of its initial capacity (Fig. 3e). Electrode kinetics was then studied to understand the good rate and cycling performance. The apparent sodium diffusion coefficient $\left(D_{\mathrm{Na}}\right)$ of HE-NASICON was primarily investigated based on CV curves (Fig. $3 f$ and Fig. S5). As displayed in Fig. 3g, the calculated $D_{\mathrm{Na}}$ fluctuates within the range of $10^{-9} \sim 10^{-10} \mathrm{~cm}^{2} \mathrm{~s}^{-1}$, which is on the same order of magnitude as most NASICON materials. Pseudocapacitance behavior investigation was further implemented and the detailed calculation process can be seen in Supporting Information (Fig. S6). It shows that at the scan rate of 1.0 $\mathrm{mV} \mathrm{s}^{-1}$, contribution of capacitance is $67.8 \%$ (Fig. $3 \mathrm{~d}$ ). Therefore, the high $\mathrm{D}_{\mathrm{Na}}$ values and contribution of pseudocapacitance should account for the satisfactory high-rate capability and cycling stability of the material. To better evaluate the performances, we then compared the electrochemical performance of the HE-NASICON with some other typical NASICON materials that previously reported. For a fair comparison, the data adopted are materials with simple carbon compositing as the HE-NASICON does. As displayed in Fig. $4 a$, in the aspect of long term cyclability, the HE-NASICON with around $0.015 \%$ capacity decay of per cycle is outstanding among the various materials. ${ }^{14,26,36,37,38,39,40,41}$ Furthermore, in terms of capacity, energy density, and average voltage, the HE-NASICON is also prominent (Fig. 4b). ${ }^{13,36,38,40,42,43,44,45}$ The multi-sodium storage contributes a high energy density approaching $500 \mathrm{Wh} \mathrm{kg}^{-1}$, making the material promising for application of grid-scale energy storage systems.

Sodium-storage mechanism. To unveil underlying effect of high-entropy on the advanced sodium storage properties, the HE-NASICON was subjected to in-situ XRD to probe crystal structure evolution of the multisodium storage reaction in the voltage range from $1.5 \mathrm{~V}$ to $4.5 \mathrm{~V}$ vs. $\mathrm{Na}^{+} / \mathrm{Na}$. Contour map and the corresponded charge/discharge curves of the cell are presented (Fig. 5a and Fig. 5b). According to the number of peaks reflection and position, the whole sodium storage reaction can be divided into 3 regions. To portray the reaction process, ex-situ XRD of a HE-NASICON electrode discharged to $1.5 \mathrm{~V}$ was primarily analyzed to disclose crystal structure of the material (Fig. 5c), and the diffraction peaks were identified based on Rietveld refinement results (Table S4). The peak at around $13.9^{\circ}, 19.8^{\circ}, 20.2^{\circ}, 23.6^{\circ}$, and $24.2^{\circ}$ is assigned to (10-2), (104), (110), (113), and (006) reflection, respectively. In region I, the (104) and (110) reflections are very close, leading to a merged broad peak, while the (112) and (006) reflections can be identified clearly. As sodium-ions continue to be extracted, in region II, the (104) and (110) separate out from the broad peak while the (112) and (006) merge together. The peaks greatly shift to higher angle when it goes to region III, indicating relatively large crystal structure variation in the high voltage region. For cathode materials, unfavorable crystal structure variation may appear and damage electrochemical performance. Therefore, crystal phase of the HE-NASICON electrode at $4.5 \mathrm{~V}$ was further studied (Fig. $5 \mathrm{~d}$ ) 
and details of the Rietveld refinement results are listed in Table S5. The fully charged electrode material can also be indexed to a trigonal $R-3 c$ phase, which is the same as the electrode at $1.5 \mathrm{~V}$, indicating that the crystal framework has no significant changes during the charge process. The diffraction peaks variation of HE-NASICON is believed to associate with the changes of content of $\mathrm{Na}^{+}$, valence of transition metals, and their local environments in the host structure. ${ }^{[29,43]}$ The lattice variation in high voltage does not affect reversibility of the material. When discharging to $1.5 \mathrm{~V}$, the XRD recovers to the original state, demonstrating an iso-symmetric reaction pattern as shown in the contour map (Fig. 5a). The peaks shifting and intensity changes should be ascribed to lattice expanding/shrinking and slight local environmental rearrangement during sodium-ion extraction/insertion. ${ }^{40}$ To confirm it, crystal structure of the electrode before charging (Fig. 5e), fully charged electrode (Fig. 5f), and fully discharged electrode (Fig. S7) were characterized by ACTEM. FFT patterns of the electrodes are both identified to be the trigonal phase along zone-axis of [42-1], suggesting that the samples possess the same crystal phase, and show the same exposing facets. The lattice spacing is measured to be $0.647 \mathrm{~nm}$ and 0.613 $\mathrm{nm}$ for the sample of $1.5 \mathrm{~V}$ and $4.5 \mathrm{~V}$, respectively. The decreased spacing confirms lattice shrinkage of the material when sodium-ions are extracted. When the electrode was fully discharged from $4.5 \mathrm{~V}$ to $1.5 \mathrm{~V}$, the lattice spacing returned to $0.644 \mathrm{~nm}$ (Fig. S7), confirming reversible lattice variation in the stable highentropy NASIOCN crystal structure. As shown in Fig. 5g-i, lattice parameter changes of the HE-NASICON during the reaction are reversible.

Based on analysis results of the crystal phase evolution, reaction mechanism of the multi-sodium storage process in HE-NASICON was plotted in Fig. 6a. The pristine HE-NASICON, which contains 3.4 sodium ions, was initially discharged to obtain a sodium-rich phase $\mathrm{Na}_{3.4+x}\left(\mathrm{Fe}_{0.4} \mathrm{Mn}_{0.4} \mathrm{~V}_{0.4} \mathrm{Ti}_{0.4} \mathrm{Cr}_{0.4}\right)\left(\mathrm{PO}_{4}\right)_{3}(\mathrm{HEN}-$ $\mathrm{Na}_{3.4+\mathrm{x}}$ ). The refined $\mathrm{x}$ value is determined to 0.743 for the material at $1.5 \mathrm{~V}$ (Table S4). In the pristine HENASICON structure, $\mathrm{Na}$-ions locate at $\mathrm{Na} 1$ and $\mathrm{Na} 2$ sites. The extra inserted sodium-ions in $\mathrm{HE}-\mathrm{Na}_{4.143}$ partially enters into the $\mathrm{Na} 1$ stie, increasing the occupancy factor of $\mathrm{Na} 1$ from 0.539 to 0.705 . While other inserted sodium-ions settle in a new Na3 site (36f). It has been reported that the coulombic repulsion, which is caused by simultaneous occupation of neighboring $\mathrm{Na} 1$ and $\mathrm{Na} 2$ sites, would lead sodium-ions to the Na3 site. ${ }^{38}$ The fully charged sodium-deficient phase is determined to be $\mathrm{Na}_{1.251}\left(\mathrm{Fe}_{0.4} \mathrm{Mn}_{0.4} \mathrm{~V}_{0.4} \mathrm{Ti}_{0.4} \mathrm{Cr}_{0.4}\right)\left(\mathrm{PO}_{4}\right)_{3}\left(\mathrm{HEN}-\mathrm{Na}_{1.251}\right)$, where the $\mathrm{Na}^{+}$ions at $\mathrm{Na} 3$ are fully extracted (Table $\mathrm{S} 5$ ). The number of sodium ions participate in energy storage is then calculated to 2.892 , verifying a multi-sodium storage reaction as anticipated. Note that, the overall volume change of the multi-sodium storage in HE-NASICON material is only $4.07 \%$. Compared to some typical low entropy NASICON structured material (with only one or two TMs), such as $\mathrm{Na}_{4} \mathrm{MnV}\left(\mathrm{PO}_{4}\right)_{3}, \mathrm{Na}_{2} \mathrm{TiV}\left(\mathrm{PO}_{4}\right)_{3}$, and $\mathrm{Na}_{4} \mathrm{MnCr}\left(\mathrm{PO}_{4}\right)_{3}$, etc. volume change of the HE-NASICON for multi-sodium storage is greatly reduced (Fig. 6b). ${ }^{11,16,26,38,39,43,45,46,47,48}$ That is critically important for the cyclability of the material. The electrode after 1000 cycles at $5 \mathrm{C}$ was further characterized to verify stability of the material. Crystal phase of the electrode after the long cycling was firstly checked by XRD, and it shows that crystal phase of the material maintains well (Fig. S8). The robust microstructure of carbon coated trigonal NASICON lattice after long cycling was determined by HR-TEM (Fig. S9). EDS shows that the atomic ratio of the 3d- 
transition-metals is almost equal (Fig. S10), and all the elemental components still uniformly distributed in the material (Fig. 6c), indicating that no phase segregation or metal-dissolution was found. Therefore, the HE-NASICON material is highly stable to afford long time running. The high-entropy strategy is suggested to present multi-functions to improve the electrochemical properties of NASICON material, as illustrated in Fig. 6d. The high-entropy effect can help to increase the solid solubility of different elements in one phase, and strain effect in high-entropy materials, which is caused by the rich accommodated atoms with different sizes, leading to an intense lattice strain field that suppress large phase transition and lattice variation. ${ }^{19}$ As a result, unfavorable crystal phase transition is suppressed in the high-entropy material even when it is charged to the high voltage of $4.5 \mathrm{~V}$. Besides, volume changes of multi-sodium storage can be greatly reduced.

Interaction between the diverse transition metals also has fundamental impact on the properties of HENASICON, such as redox activity. To understand it, valent states of the TMs in the pristine electrode, fully discharged electrode and fully charged electrode were analyzed by ex-situ XPS to determine the electrochemically active species during the sodium-storage reaction (Fig. 7a). For Fe $2 p_{3 / 2}$ and $M n 2 p_{3 / 2}$, their profiles present no significant changes between pristine and fully discharged electrodes, indicating that $\mathrm{Fe}$ and $\mathrm{Mn}$ do not participate redox reaction during the initial discharge process that presented in Fig. 3a. While when fully charged, the intensity of $\mathrm{Fe}^{2+}(711.75 \mathrm{eV})$ decreases and $\mathrm{Fe}^{3+}(715.21 \mathrm{eV})$ increases obviously, manifesting $\mathrm{Fe}^{2+} / \mathrm{Fe}^{3+}$ redox reaction happens in the charge process. The $\mathrm{Mn} 2 \mathrm{p}_{3 / 2}$ was found to shift to higher binding energy and two main peaks at $642.33 \mathrm{eV}\left(\mathrm{Mn}^{3+}\right)$ and $643.38 \mathrm{eV}$ $\left(\mathrm{Mn}^{4+}\right)$ appeared when fully charged, indicating that the $\mathrm{Mn}^{2+}$ was oxidated to a $\mathrm{Mn}^{3+} / \mathrm{Mn}^{4+}$ mixed state. ${ }^{49}$ Different from Fe and $\mathrm{Mn}, \mathrm{V}$ and $\mathrm{Ti}$ are active during the initial discharge process, as evidenced by the clear intensity increase of $\mathrm{V}^{2+}(515.31 \mathrm{eV})$ and $\mathrm{Ti}^{3+}(458.98 \mathrm{eV})$ species in $\mathrm{V} 2 \mathrm{p}_{3 / 2}$ and $\mathrm{Ti} 2 \mathrm{p}_{3 / 2}$

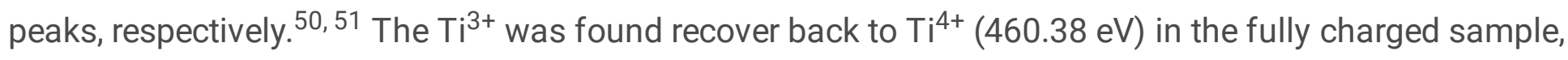
while the $\mathrm{V}^{2+}$ was oxidated to $\mathrm{V}^{5+}(518.11 \mathrm{eV})$ and $\mathrm{V}^{4+}(516.99 \mathrm{eV})$, implying that the $\mathrm{V}$ undergoes continuous redox reactions. ${ }^{40,52} \mathrm{Cr} 2 \mathrm{p}_{3 / 2}$ is the only $\mathrm{TM}$ species that almost has no changes during the whole reaction. The XPS results verify the multi active TM centers and multi-redox reactions in the HENASICON material, which is in accordance with the multi voltage platforms of the charge/discharge profiles. To further revel the roles of the transition metals to electrochemical performance, five highentropy NASICON materials with doubled concentration of $\mathrm{Fe}, \mathrm{Mn}, \mathrm{V}, \mathrm{Ti}$, and $\mathrm{Cr}$ (noted as HEN-Fe, HENMn, HEN-V, HEN-Ti, HEN-Cr, respectively) were synthesized. All of the samples show the same crystal phase as the HE-NASICON (Fig. S11). EDS mapping demonstrates that the atomic ratios of the elements are close to their theoretical values and the elements are evenly distributed, indicating successful synthesis of the diverse high-entropy materials (Fig. S12-16). Carbon content of the materials were determined by TG (Fig. S17) and were ruled out when counting their sodium storage capacities.

Galvanostatic charge/discharge profiles of the samples at $0.1 \mathrm{C}$ are presented in Fig. S18. The discharge capacity of HEN-Fe, HEN-Mn, HEN-V, HEN-Ti, and HEN-Cr is 153.2, 144.0, 150.8, 140.7, and $153.0 \mathrm{~mA} h$ $\mathrm{g}^{-1}$, respectively. All the discharge curves show multiple terraces. To analyze capacity contributions in different voltage regions, the profiles are divided into 5 regions highlighted with different colors, as 
demonstrated in Fig. 7b. Larger capacity contributions in the high voltage regions of $3.5 \sim 4.0 \mathrm{~V}$ and 4.0 $\sim 4.5 \mathrm{~V}$ are found in HEN-Mn and HEN-Cr, indicating that $\mathrm{Mn}$ and $\mathrm{Cr}$ are beneficial to achieve high voltage properties of the material (Fig. 7c). Rate performance and cycling capability of the materials are exhibited in Fig. $7 d$ and Fig. S19. For HEN-Fe, although it has relatively large capacity at $0.1 \mathrm{C}$, its rate performance is poor, with only $49.9 \mathrm{~mA} \mathrm{~h} \mathrm{~g}^{-1}$ at $20 \mathrm{C}$. The HEN-Mn shows the worst rate capability, which is probably because of the relatively sluggish electrode kinetics as many Mn-based materials reported. ${ }^{6,53}$ In the contrast, the HEN-Ti possess the highest capacity of $62.81 \mathrm{~mA} \mathrm{~h} \mathrm{~g}^{-1}$ at $20 \mathrm{C}$, regardless the relatively low capacity at $0.1 \mathrm{C}$. Besides, HEN-Ti also demonstrates the best cycling performance, with a remarkable capacity retention of $90.92 \%$ after 1000 cycles at $5 \mathrm{C}$ (Fig. 7e). While the capacity of HEN-Cr decays very fast. Therefore, the TMs show different features affecting the materials in terms of capacity, voltage, rate capability, and cycling stability. It is the synergistic effect of TMs with suitable molarity and high-entropy finally leads to the HE-NASICON material with high performances.

\section{Discussion}

A high-entropy NASICON structure $\mathrm{Na}_{3.4} \mathrm{Fe}_{0.4} \mathrm{Mn}_{0.4} \mathrm{~V}_{0.4} \mathrm{Cr}_{0.4} \mathrm{Ti}_{0.4}\left(\mathrm{PO}_{4}\right)_{3}$, material was successfully synthesized through a facile sol-gel method. The HE-NASICON is found to possess multi-redox reactions due to the diverse TMs species and overcome the stability and reversibility issues of general polyanion type cathode materials. In-situ XRD analysis shows that crystal phase of the HE-NASICON during the multi-sodium storage reaction is stable, and the volume change is only $4.07 \%$. It is suggested that the high-entropy effect can help to stabilize the host framework of NASICON structure, thus leading to the enhanced cyclability. By comparing a group of HE-NASICON cathodes containing different contents of TM species, we further demonstrate the advanced electrochemical performance of HE-NASICON also derives from the synergistic effect of the various transition metals with equal molarity. The high-entropy strategy on NASICON opens a new opportunity to design advanced polyanion compounds for SIBs.

\section{Methods}

Synthesis of HE-NASICON and other high-entropy NASICON materials with different atomic ratio. The HENASICON was synthesized by a typical sol-gel method. All chemical reagents were used without further purification. Iron nitrate nonahydrate, manganese acetate, ammonium metavanadate, titanium (IV) isopropoxide, and chromium(III) nitrate nonahydrate were used as the $\mathrm{Fe}, \mathrm{Mn}, \mathrm{V}, \mathrm{Ti}, \mathrm{Cr}$ sources, respectively. Firstly, stoichiometric amount of anhydrous citric acid and ammonium metavanadate are dissolved in $20 \mathrm{~mL}$ deionized water, forming solution $\mathrm{A}$. Then, sodium carbonate and the $\mathrm{Fe}, \mathrm{Mn}, \mathrm{Cr}$ sources are added in another $40 \mathrm{~mL}$ deionized water, forming solution $\mathrm{B}$. A was then mixed with $\mathrm{B}$ at 80 ${ }^{\circ} \mathrm{C}$ and kept constant stirring for $30 \mathrm{~min}$. After that, ammonium biphosphate were added into the mixed solution. When the ammonium biphosphate was fully dissolved, appropriate amount of titanium (IV) isopropoxide that dissolved in $20 \mathrm{~mL}$ absolute ethanol was finally added into the mixed solution drop by drop. The final solution kept constant stirring at $80^{\circ} \mathrm{C}$ until a gel was formed. The gel was dried at 120 ${ }^{\circ} \mathrm{C}$ in an oven. Finally, the porous precursor was calninated at $700{ }^{\circ} \mathrm{C}$ for $12 \mathrm{~h}$ under $\mathrm{Ar}$ to obtain the HE- 
NASICON material. Other high-entropy NASICON materials with different atomic ratio were also synthesized through the same sol-gel route. The amounts of reagents used to synthesize the materials are listed in Table S1.

Materials characterization. X-ray diffraction (XRD) data and were collected from $10^{\circ}$ to $80^{\circ}$ in PANalytical Empyrean 2. The XRD refinements were conducted by GSAS software. Morphology and composition of the materials was disclosed by field-emission scanning electron microscopy (SEM, JSM-IT300LA) equipped with energy-dispersive X-ray spectroscopy (EDS). Micro-structure of materials was further studied by spherical-aberration-corrected transmission electron microscopy (ACTEM, Titan G2 60-300). Electron diffraction images were got by Fast Fourier Transform (FFT). Valence states of Fe, Mn, V, Ti and Cr were determined by X-ray photoelectron spectroscopy (XPS, ESCALAB 250Xi). Raman measurements were performed on LabRAM HR Evolution. Carbon content of the materials were determined by thermogravimetric (TG) analysis from room temperature to $650^{\circ} \mathrm{C}$ with a heating rate of $10^{\circ} \mathrm{C} \mathrm{min}{ }^{-1}$ under air atmosphere.

Electrochemical measurements. For the fabrication of electrodes for electrochemical performance tests, the active materials, carbon black and polyvinylidene fluoride (PVDF) with a weight ratio of 7: 2: 1 were mixed in appropriate amount of 1-Methyl-2-pyrrolidinone (NMP) to make a slurry. The slurry was costed on Al foil and dried at $80^{\circ} \mathrm{C}$. Loading mass of active materials was in the range of $1.2 \sim 1.4 \mathrm{mg} \mathrm{cm}^{-2}$. Na metal and glass fiber filters (Whatman) were used as counter electrode and separator, respectively. $1 \mathrm{M}$ $\mathrm{NaClO}_{4}$ dissolving in PC solution with 5 vol\% addition of fluoroethylene carbonate (FEC) was used as the electrolyte. Electrochemical performance of the cells was carried out on a Land battery testing system $(\mathrm{CT} 2001 \mathrm{~A})$ within the voltage range of $4.5-1.5 \mathrm{~V}\left(\mathrm{vs} . \mathrm{Na} / \mathrm{Na}^{+}\right)$.

\section{Declarations}

Acknowledgements

The authors thank the financial support from the Natural Science Foundation of Hunan Province, China (2020JJ1007) and the Anhui Province Research and Development Innovation Project for Automotive Power Battery Efficient Recycling System.

\section{Data availability}

Data supporting the findings of this study are available from the authors on reasonable request.

\section{Author contributions}


H. Li prepared the manuscript. H. Li and J. Zheng synthesized the materials. L. Zhang and Y. Xie carried out the in-situ XRD. H. Long and K. Yuan helped to analyze data. S. Li drew the schematic and J. Guo helped to conduct TEM. H. Li and M. Xu co-wrote the manuscript. Y. Lai and Z. Zhang supervised the project. All authors discussed the results and contributed to writing the manuscript.

\section{Additional information}

Supplementary Information accompanies this paper at https://

\section{Competing interests}

The authors declare no competing interests.

\section{References}

1. Duffner F, Kronemeyer N, Tübke J, Leker J, Winter M, Schmuch R. Post-lithium-ion battery cell production and its compatibility with lithium-ion cell production infrastructure. Nat. Energy 6, 123134 (2021).

2. Usiskin R, et al. Fundamentals, status and promise of sodium-based batteries. Nat. Rev. Mater. 6, 1020-1035 (2021).

3. Tian Y, et al. Promises and Challenges of Next-Generation "Beyond Li-ion" Batteries for Electric Vehicles and Grid Decarbonization. Chem. Rev. 121, 1623-1669 (2021).

4. Fan E, et al. Sustainable Recycling Technology for Li-lon Batteries and Beyond: Challenges and Future Prospects. Chem. Rev. 120, 7020-7063 (2020).

5. Jiang L, et al. High-Voltage Aqueous Na-Ion Battery Enabled by Inert-Cation-Assisted Water-in-Salt Electrolyte. Adv. Mater. 32, e1904427 (2020).

6. Li H, et al. Manganese-Based Materials for Rechargeable Batteries beyond Lithium-lon. Adv. Energy Mater. 11, 2100867 (2021).

7. Xiang X, Zhang K, Chen J. Recent Advances and Prospects of Cathode Materials for Sodium-lon Batteries. Adv. Mater. 27, 5343-5364 (2015).

8. Hwang JY, Myung ST, Sun YK. Sodium-ion batteries: present and future. Chem. Soc. Rev. 46, 35293614 (2017).

9. Chen S, et al. Challenges and Perspectives for NASICON-Type Electrode Materials for Advanced Sodium-lon Batteries. Adv. Mater. 29, 1700431 (2017). 
10. Ni Q, Bai Y, Wu F, Wu C. Polyanion-Type Electrode Materials for Sodium-lon Batteries. Adv. Sci. 4, 1600275 (2017).

11. Liu R, et al. Exploring Highly Reversible 1.5-Electron Reactions $(\mathrm{V}(3+) / \mathrm{V}(4+) / \mathrm{V}(5+))$ in $\mathrm{Na} 3 \mathrm{VCr}(\mathrm{PO} 4) 3$ Cathode for Sodium-lon Batteries. ACS Appl. Mater. linterf. 9, 43632-43639 (2017).

12. Xu C, et al. A Novel NASICON-Typed Na4VMn0.5Fe0.5(PO4)3 Cathode for High-Performance Na-lon Batteries. Adv. Energy Mater.11, 2100729 (2021).

13. Zhou W, et al. NaxMV(PO4)3 ( $\mathrm{M}=\mathrm{Mn}, \mathrm{Fe}, \mathrm{Ni})$ Structure and Properties for Sodium Extraction. Nano Lett. 16, 7836-7841 (2016).

14. Li H, et al. Rational Architecture Design Enables Superior Na Storage in Greener NASICONNa4MnV(P04)3 Cathode. Adv. Energy Mater. 8, 1801418 (2018).

15. Zakharkin MV, et al. Enhancing Na+ Extraction Limit through High Voltage Activation of the NASICON-Type Na4MnV(P04)3 Cathode. ACS Appl. Energy Mater. 1, 5842-5846 (2018).

16. Chen F, et al. A NASICON-Type Positive Electrode for Na Batteries with High Energy Density: Na4MnV(P04)3. Small Met. 3, 1800218 (2018).

17. Ma Y, et al. High-entropy energy materials: challenges and new opportunities. Energy Environ. Sci. 14, 2883-2905 (2021).

18. Sun Y, Dai S. High-entropy materials for catalysis: A new frontier. Sci. Adv. 7, (2021).

19. Chen Y, et al. Opportunities for High-Entropy Materials in Rechargeable Batteries. ACS Mater. Lett. 3 , 160-170 (2020).

20. Ye YF, Wang Q, Lu J, Liu CT, Yang Y. High-entropy alloy: challenges and prospects. Mater. Today 19, 349-362 (2016).

21. Sarkar A, et al. High entropy oxides for reversible energy storage. Nat. Commun.9, 3400 (2018).

22. Lun Z, et al. Cation-disordered rocksalt-type high-entropy cathodes for Li-ion batteries. Nat. Mater. 20, 214-221 (2021).

23. Zhao C, Ding F, Lu Y, Chen L, Hu YS. High-Entropy Layered Oxide Cathodes for Sodium-Ion Batteries. Angew. Chem. 59, 264-269 (2020).

24. Cavin J, et al. 2D High-Entropy Transition Metal Dichalcogenides for Carbon Dioxide Electrocatalysis. Adv. Mater. 33, e2100347 (2021).

25. Ma Y, et al. High-Entropy Metal-Organic Frameworks for Highly Reversible Sodium Storage. Adv. Mater. 33, e2101342 (2021).

26. $\mathrm{Li} \mathrm{H}$, et al. Highly efficient, fast and reversible multi-electron reaction of $\mathrm{Na} 3 \mathrm{MnTi}(\mathrm{PO} 4) 3$ cathode for sodium-ion batteries. Energy Storage Mater. 26, 325-333 (2020).

27. Zhang W, Liaw PK, Zhang Y. Science and technology in high-entropy alloys. Sci. Chin. Mater. 61, 222 (2018).

28. Li H, et al. Scalable Synthesis of the Na2FePO4F Cathode Through an Economical and Reliable Approach for Sodium-lon Batteries. ACS Sus. Chem. Eng. 9, 11798-11806 (2021). 
29. Wang W, et al. A high voltage cathode of $\mathrm{Na} 2+2 x \mathrm{Fe} 2-x(\mathrm{SO} 4) 3$ intensively protected by nitrogendoped graphene with improved electrochemical performance of sodium storage. J. Mater. Chem. A6, 4354-4364 (2018).

30. Choi $\mathrm{D}$, et al. Thermal stability and phase transformation of electrochemically charged/discharged LiMnPO4 cathode for Li-ion batteries. Energy Environ. Sci. 4, 4560 (2011).

31. Zhang W, Li H, Zhang Z, Xu M, Lai Y, Chou SL. Full Activation of Mn(4+) /Mn(3+) Redox in Na4 $\mathrm{MnCr}(\mathrm{PO} 4) 3$ as a High-Voltage and High-Rate Cathode Material for Sodium-Ion Batteries. Small 16, e2001524 (2020).

32. Zhang W, et al. Engineering 3D Well-Interconnected Na4MnV(PO4)3 Facilitates Ultrafast and Ultrastable Sodium Storage. ACS Appl. Mater. Interf. 11, 35746-35754 (2019).

33. Zhu T, et al. Realizing Three-Electron Redox Reactions in NASICON-Structured Na3MnTi(PO4)3 for Sodium-Ion Batteries. Adv. Energy Mater. 9, 1803436 (2019).

34. Li H, et al. Pseudocapacitance enhanced by N-defects in $\mathrm{Na3MnTi(PO4)3/N-doped} \mathrm{carbon}$ composite for symmetric full sodium-ion batteries. Mater. Today Energy 21, 100754 (2021).

35. Liu R, Liang Z, Gong Z, Yang Y. Research Progress in Multielectron Reactions in Polyanionic Materials for Sodium-Ion Batteries. Small Met. 3, 1800221 (2018).

36. Liu Y, Zhou Y, Zhang J, Xia Y, Chen T, Zhang S. Monoclinic Phase Na3Fe2(P04)3: Synthesis, Structure, and Electrochemical Performance as Cathode Material in Sodium-lon Batteries. ACS Sus. Chem. Eng. 5, 1306-1314 (2016).

37. Zhao Y, Gao X, Gao H, Jin H, Goodenough JB. Three Electron Reversible Redox Reaction in Sodium Vanadium Chromium Phosphate as a High-Energy-Density Cathode for Sodium-lon Batteries. Adv. Funct. Mater. 30, 1908680 (2020).

38. Gao H, Seymour ID, Xin S, Xue L, Henkelman G, Goodenough JB. Na3MnZr(PO4)3: A High-Voltage Cathode for Sodium Batteries. J. Am. Chem. Soc. 140, 18192-18199 (2018).

39. Zhang J, et al. A Novel NASICON-Type Na4 MnCr(PO4)3 Demonstrating the Energy Density Record of Phosphate Cathodes for Sodium-Ion Batteries. Adv. Mater. 32, e1906348 (2020).

40. Wang $D$, et al. Sodium vanadium titanium phosphate electrode for symmetric sodium-ion batteries with high power and long lifespan. Nat. Commun. 8, 15888 (2017).

41. Zhu Q, et al. Microorganism-moulded pomegranate-like Na3V2(PO4)3/C nanocomposite for advanced sodium-ion batteries. J. Mater. Chem. A 5, 9982-9990 (2017).

42. Wang Q, Ling C, Li J, Gao H, Wang Z, Jin H. Experimental and theoretical investigation of $\mathrm{Na} 4 \mathrm{MnAl}(\mathrm{PO} 4) 3$ cathode material for sodium-ion batteries. Chem. Eng. J. 425, 130680 (2021).

43. Gao H, Li Y, Park K, Goodenough JB. Sodium Extraction from NASICON-Structured Na3MnTi(PO4)3 through $\mathrm{Mn}(\mathrm{III}) / \mathrm{Mn}$ (II) and Mn(IV)/Mn(III) Redox Couples. Chem. Mater. 28, 6553-6559 (2016).

44. Wang J, et al. A High-Energy NASICON-Type Cathode Material for Na-lon Batteries. Adv. Energy Mater. 10, 1903968 (2020). 
45. Jian Z, et al. Superior Electrochemical Performance and Storage Mechanism of Na3V2(P04)3Cathode for Room-Temperature Sodium-lon Batteries. Adv. Energy Mater. 3, 156-160 (2013).

46. Jiang X, Zeng Z, Xiao L, Ai X, Yang H, Cao Y. An All-Phosphate and Zero-Strain Sodium-lon Battery Based on Na3V2(PO4)3 Cathode, NaTi2(PO4)3 Anode, and Trimethyl Phosphate Electrolyte with Intrinsic Safety and Long Lifespan. ACS Appl. Mater. Interf. 9, 43733-43738 (2017).

47. Mamoor $\mathrm{M}$, et al. Identification of the structural, electronic properties, and ionic diffusion kinetics of $\mathrm{Na3Cr}$ (PO4)3 by first-principles calculations. Electrochim. Acta 379, 138157 (2021).

48. Lalère F, Seznec V, Courty M, Chotard JN, Masquelier C. Coupled X-ray diffraction and electrochemical studies of the mixed Ti/V-containing NASICON: Na2TiV(PO4)3. J. Mater. Chem. A 6, 6654-6659 (2018).

49. Klee R, Lavela P, Aragón MJ, Alcántara R, Tirado JL. Enhanced high-rate performance of manganese substituted Na 3 V 2 (PO 4) 3 /C as cathode for sodium-ion batteries. J. Power Sources 313, 73-80 (2016).

50. Liang J, Fan K, Wei Z, Gao X, Song W, Ma J. Porous NaTi2(P04)3@C nanocubes as improved anode for sodium-ion batteries. Mater. Res. Bul. 99, 343-348 (2018).

51. Xu C, et al. Carbon-coated hierarchical NaTi2(PO4)3 mesoporous microflowers with superior sodium storage performance. Nano Energy 28, 224-231 (2016).

52. Inoishi A, Yoshioka Y, Zhao L, Kitajou A, Okada S. Improvement in the Energy Density of Na3V2(P04)3 by Mg Substitution. ChemElectroChem 4, 2755-2759 (2017).

53. Park CS, et al. Anomalous manganese activation of a pyrophosphate cathode in sodium ion batteries: a combined experimental and theoretical study. J. Am. Chem. Soc. 135, 2787-2792 (2013).

\section{Figures}




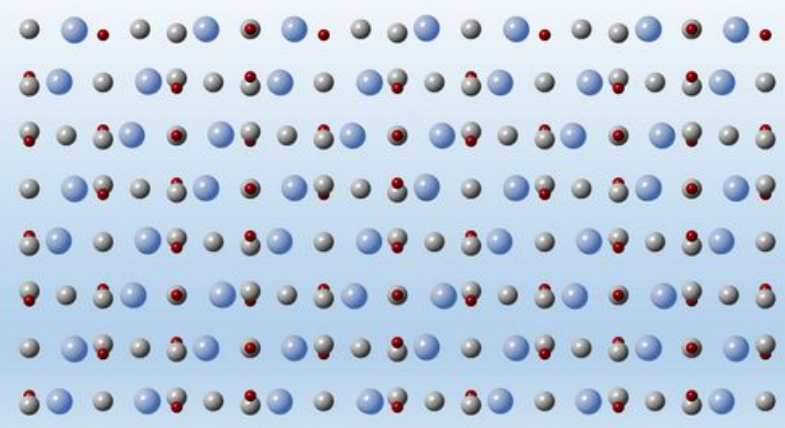

(b)

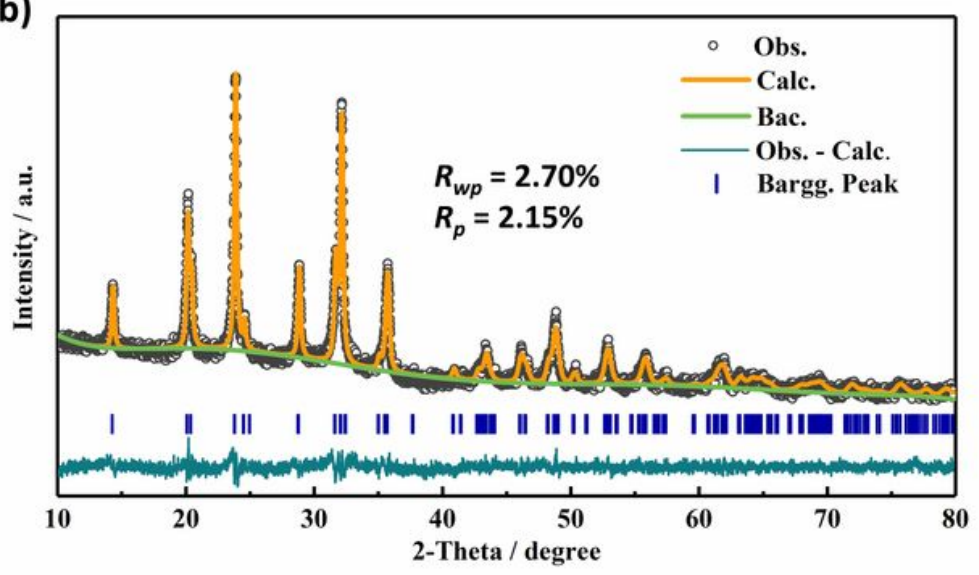

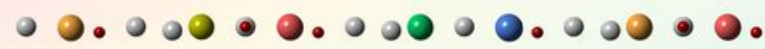

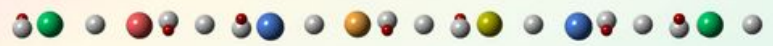

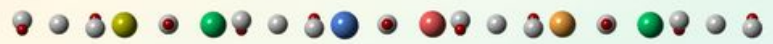

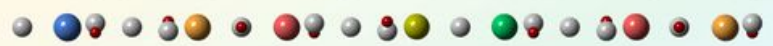

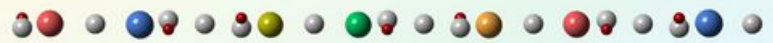

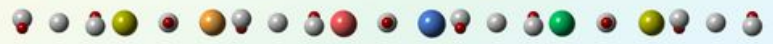

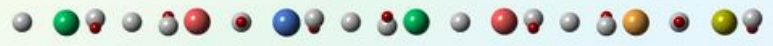

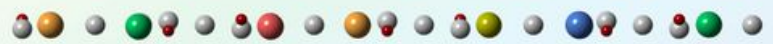

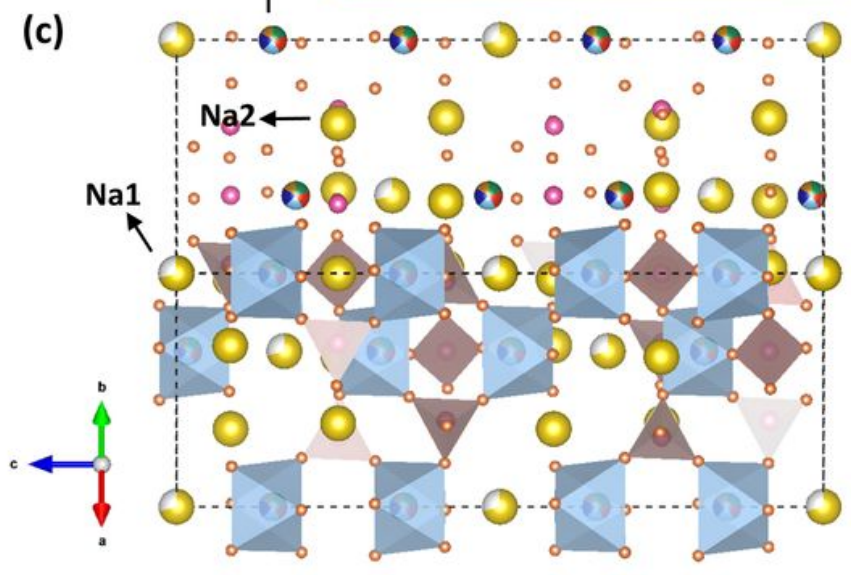

Figure 1

Crystal phase of HE-NASICON. (a) Schematic illustration of the transition-metals (TMs) distribution in NASICON structure. The grey and red balls represent $P$ and $O$ atoms, respectively. The balls with other colors represent different types of TMs. (b) Rietveld refinement profile of the HE-NASICON material. (c) Schematic illustration of the crystal structure of HE-NASICON. 


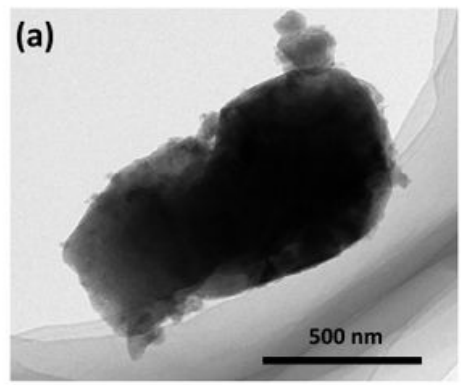

(e)

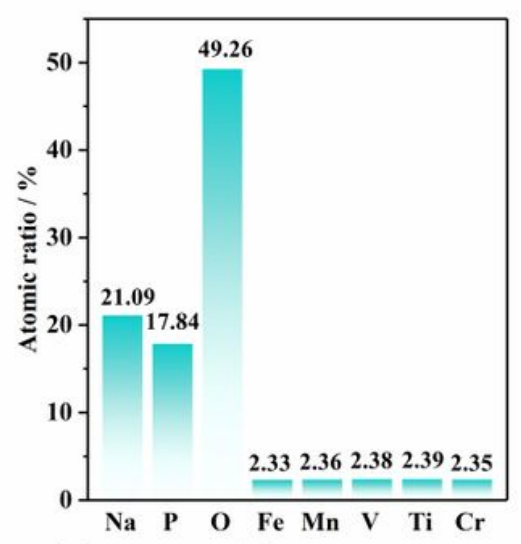

(g)

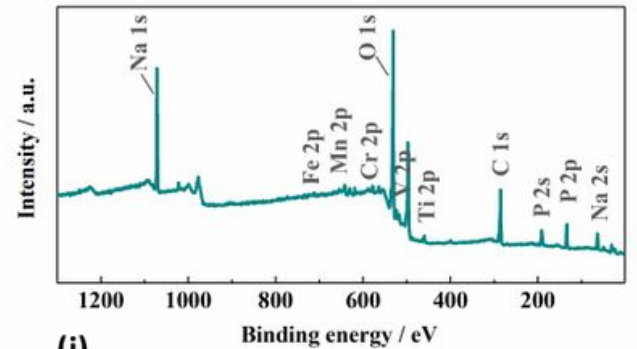

(j)

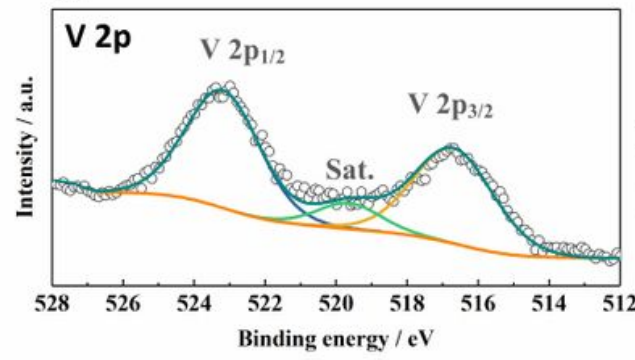

(f)
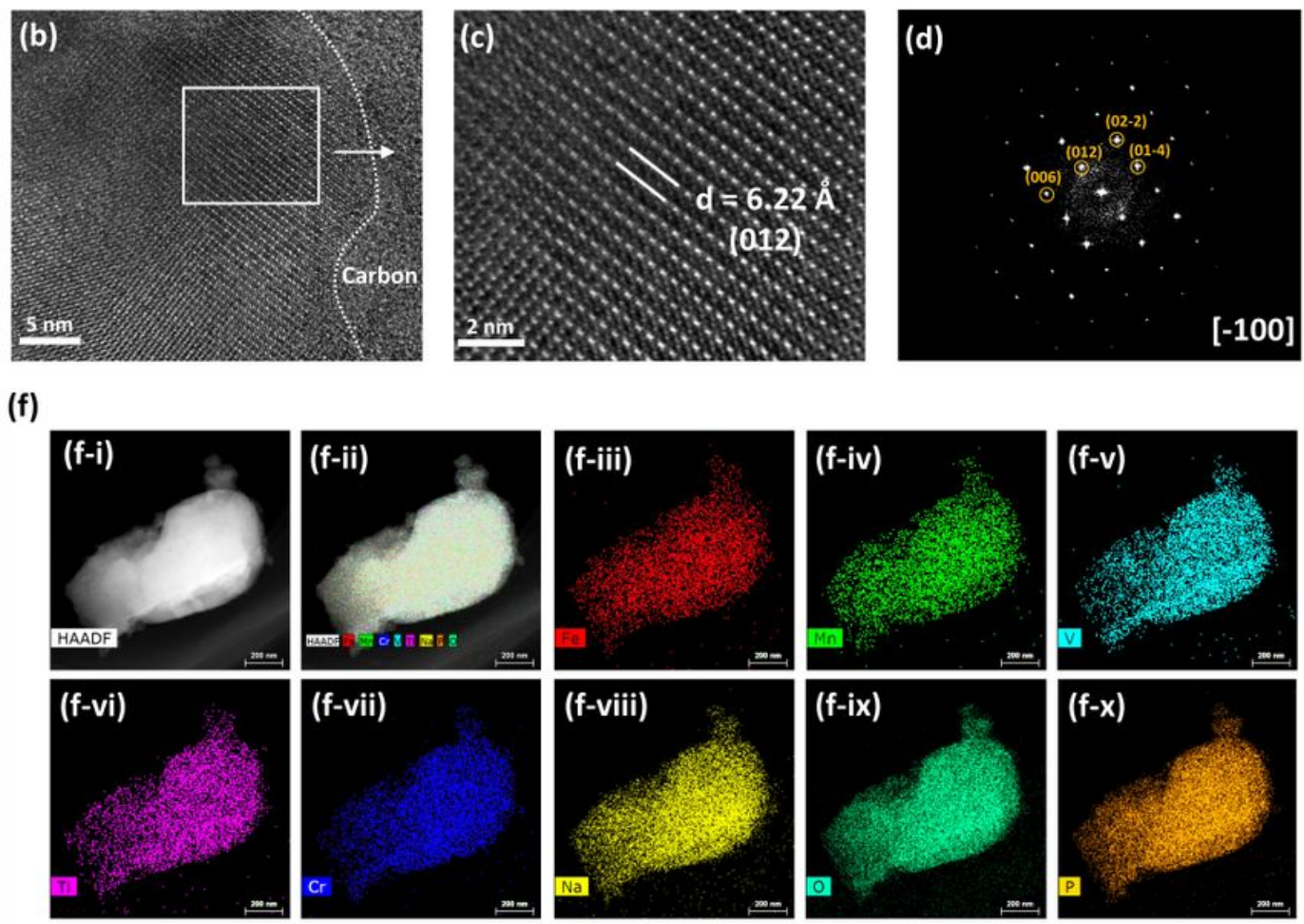

(h)
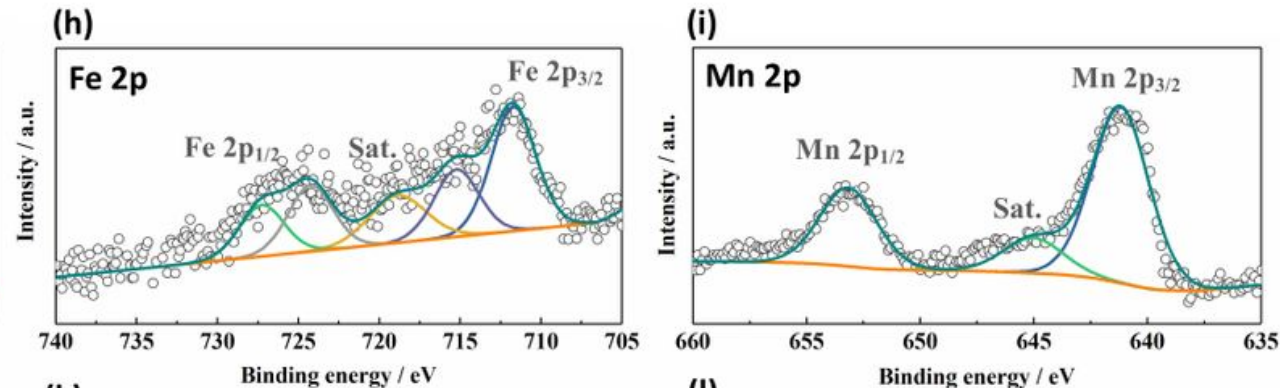

(k)

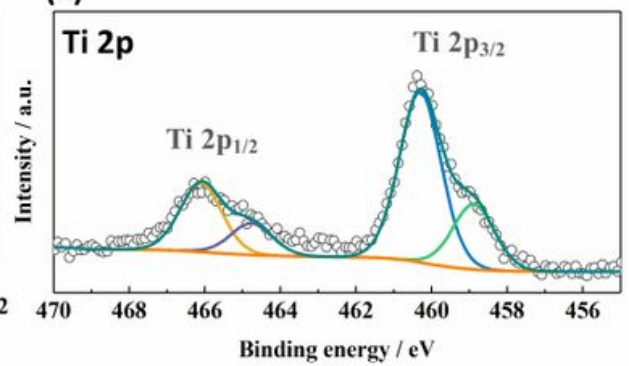

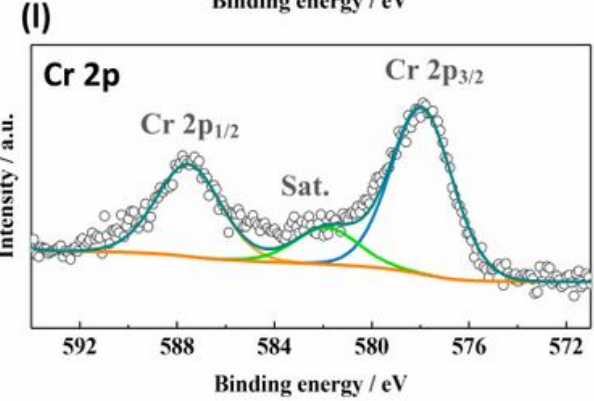

\section{Figure 2}

Physicochemical properties of the HE-NASICON. (a) TEM image, (b) high-resolution TEM (HR-TEM) image, (c) enlarged HR-TEM with clear atomic lattice and (d) the corresponded FFT pattern of the HENASICON material. (e) Atomic ratio and (f) distributions of $\mathrm{Fe}, \mathrm{Mn}, \mathrm{V}, \mathrm{Ti}, \mathrm{Cr}, \mathrm{Na}, \mathrm{O}$, and $\mathrm{P}$ elements in the HE-NASICON particle. (g) XPS survey spectrum of the HE-NASICON. (h) Fe 2p, (i) Mn 2p, (j) V 2p, (k) Ti 2p, and (I) $\mathrm{Cr} 2 \mathrm{p}$ core-level XPS spectra of HE-NASICON. 

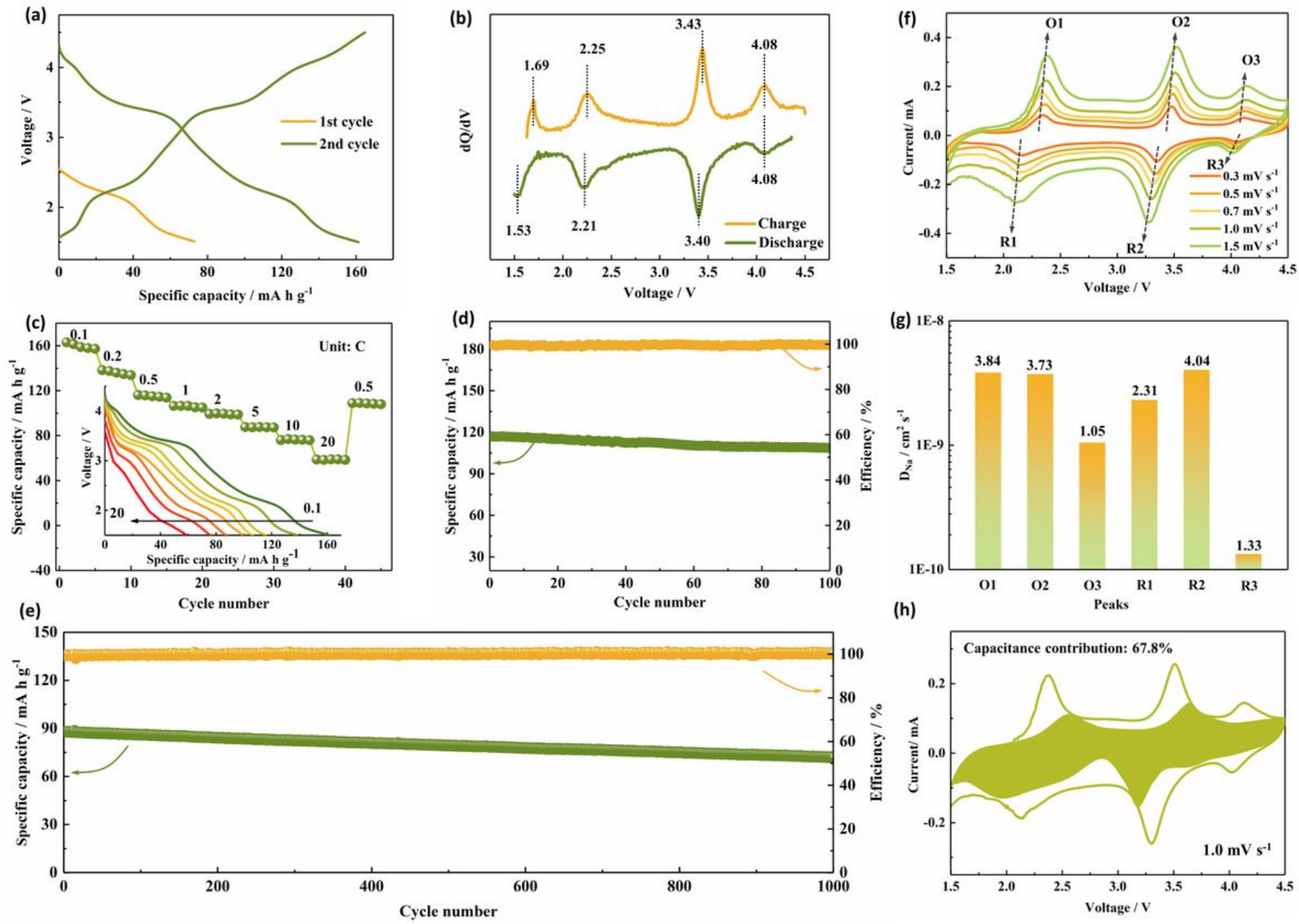

\section{Figure 3}

Electrochemical performances of the HE-NASICON cathode. (a) Charge/discharge profiles of the cathode in the first and second cycles. (b) dQ/dV plot of the cathode in the second cycle. (c) Rate performance from 0.1 to $20 \mathrm{C}$. The inset is the corresponded discharge curves at different rates. (d) Cycling performance of the HE-NASICON at $0.5 \mathrm{C}$. (e) Long cycling stability of the material at $5 \mathrm{C}$. (f) CV curves of the HE-NASICON electrode at various scan rates from $0.3 \mathrm{mV} \mathrm{s}^{-1}$ to $1.5 \mathrm{mV} \mathrm{s}^{-1}$. (g) The sodium diffusion coefficients of HE-NASICON electrode calculated basing on CV. (h) Demonstration of pseudocapacitance contribution at $1.0 \mathrm{mV} \mathrm{s}^{-1}$. 

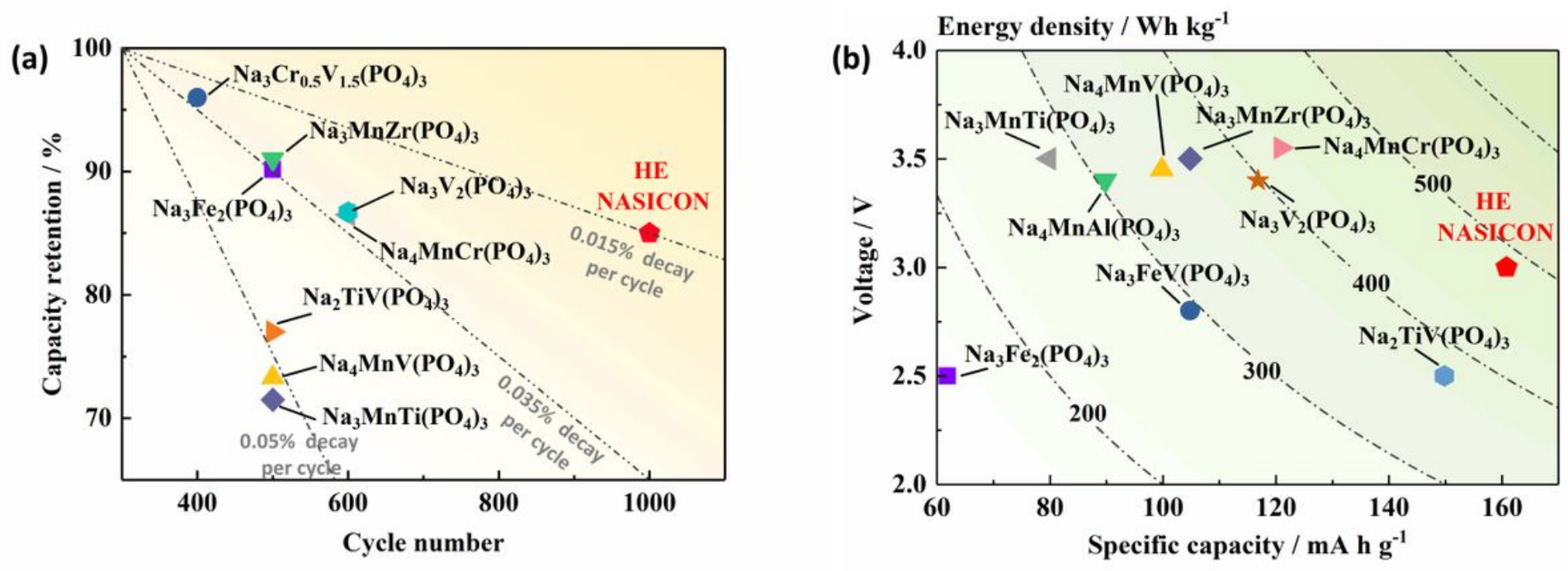

Figure 4

(a) Long term cycling stability comparison of diverse NASICON materials reported. $14,26,36,37,38,39,40,41$

(b) Energy density, specific capacity and average voltage comparison of diverse NASICON materials reported. ${ }^{13,36,38,40,42,43,44,45}$ 
(a)

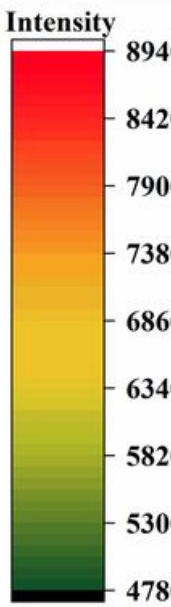

420

900

380

6860

6340

5820

5300

780
$(10-2)$

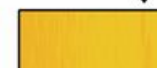

(113) (006)

(20-4)

(211) (116)

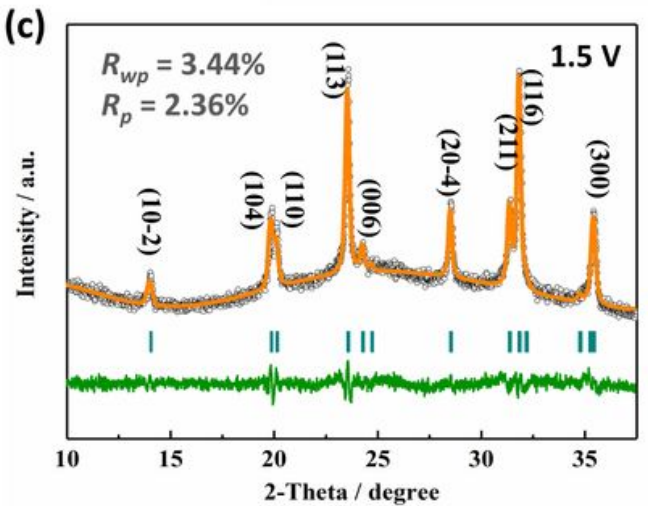

(d)

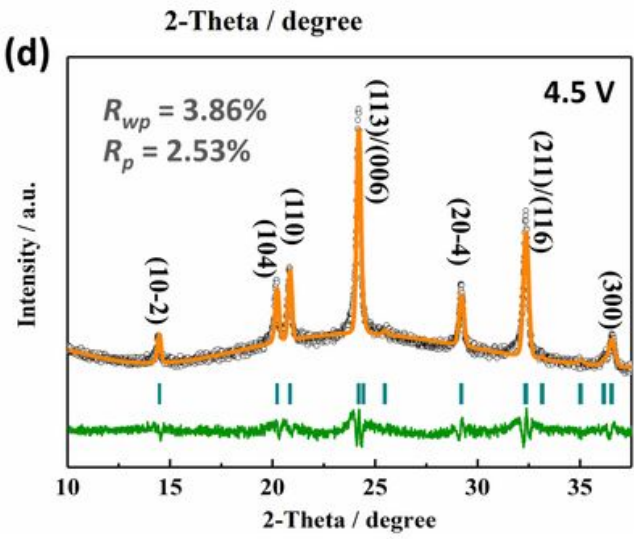

(e)
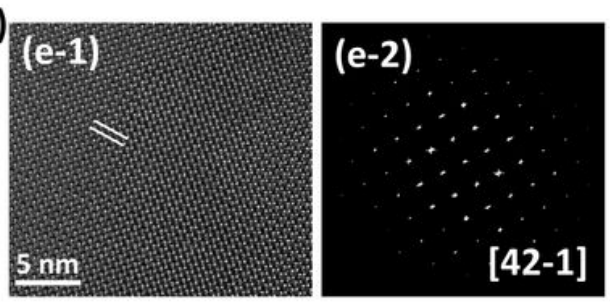

(f)
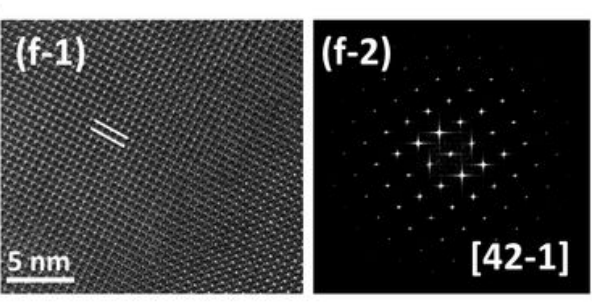

(g)

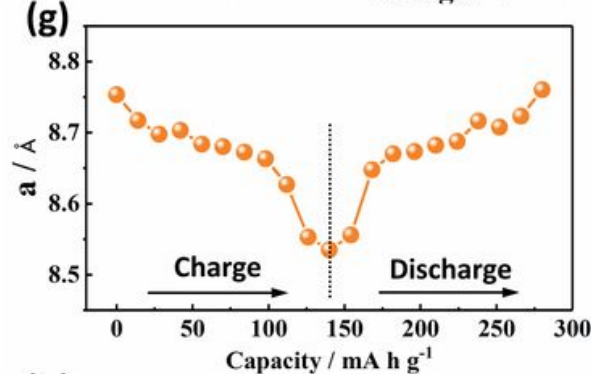

(h)
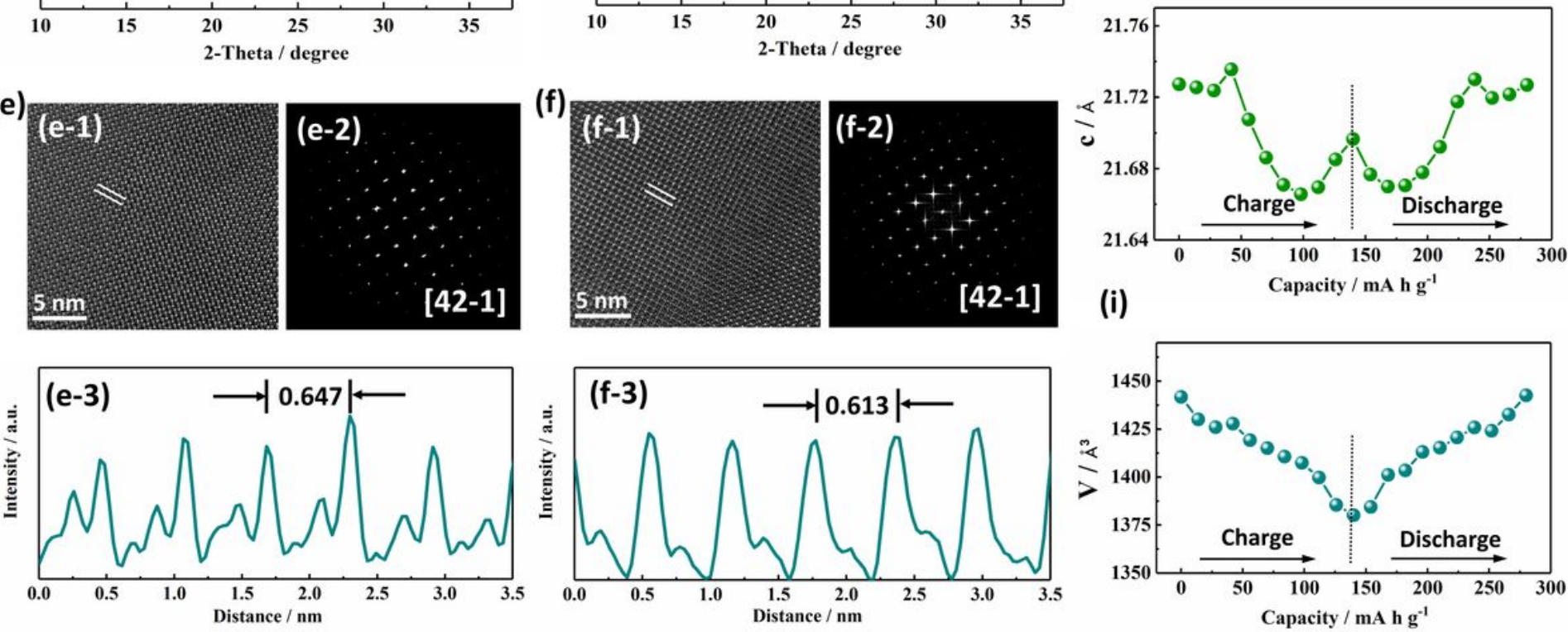

Figure 5

Characterization of the reaction process of HE-NASICON cathode. (a) Contour map of in-situ XRD pattern of the HE-NASICON electrode in the voltage range between 1.5 and $4.5 \mathrm{~V}$ (vs. $\left.\mathrm{Na}^{+} / \mathrm{Na}\right)$. (b) The corresponded charge/discharge curves of the cell operated at current density of $25 \mathrm{~mA} \mathrm{~g}^{-1}$. (c) XRD pattern of the electrode discharged at $1.5 \mathrm{~V}$. (d) XRD pattern of the electrode charged at 4.5 V. (e) Lattice structure of the electrode at $1.5 \mathrm{~V}$. (e-1) The HR-TEM and (e-2) the corresponded FFT pattern. (e-3) Integrated pixel intensities collected from e-1. (f) Lattice structure of the electrode at 4.5 V. (f-1) The HR- 
TEM and (f-2) the corresponded FFT pattern. (f-3) Integrated pixel intensities collected from i-1. (g) The variation of cell parameters of $a,(h) c$, (i) V.

(a)

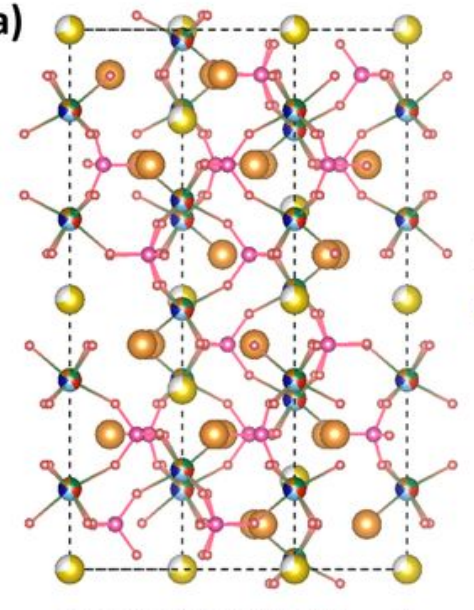

HE-NASICON $\left(\mathrm{Na}_{3.40}\right)$

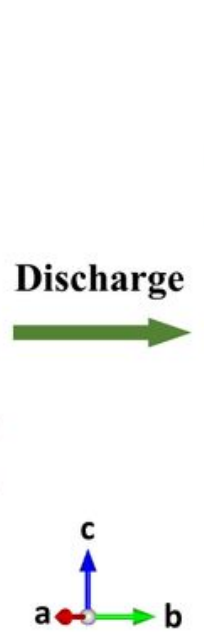

(b)

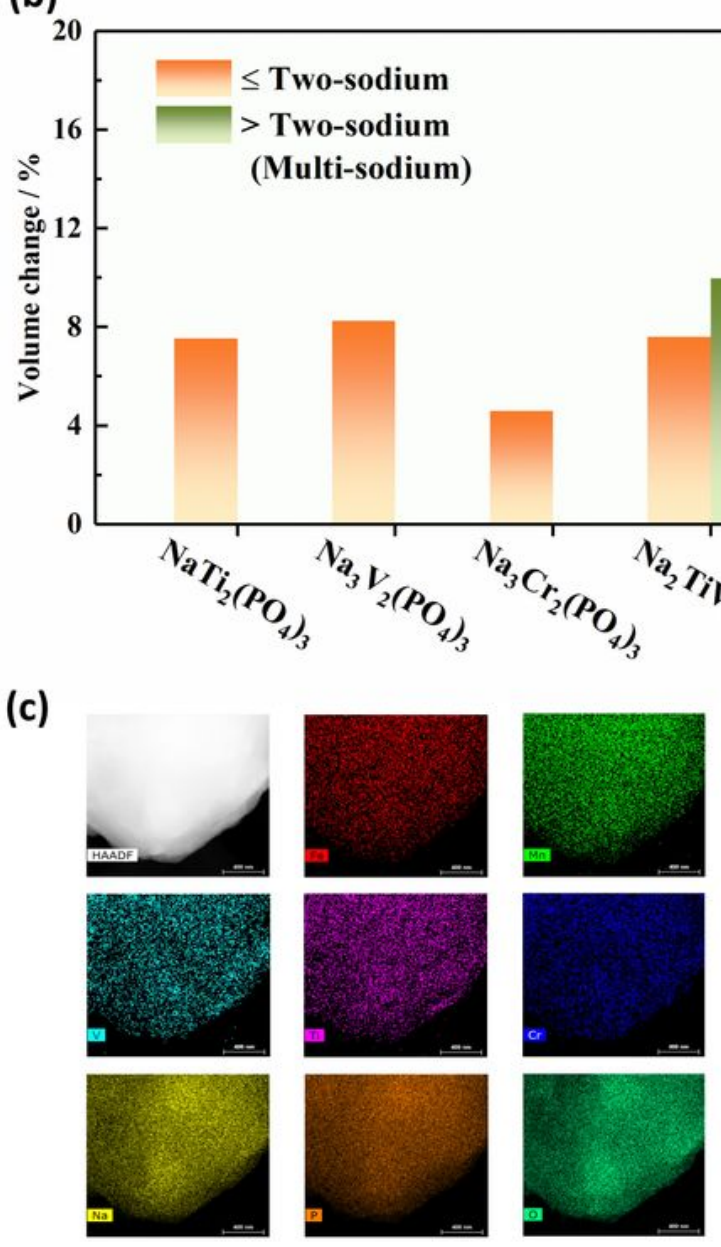

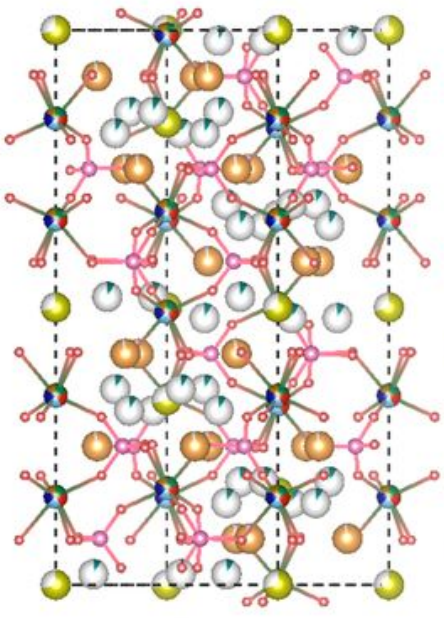

HE-Na $\mathbf{a}_{4.143}$

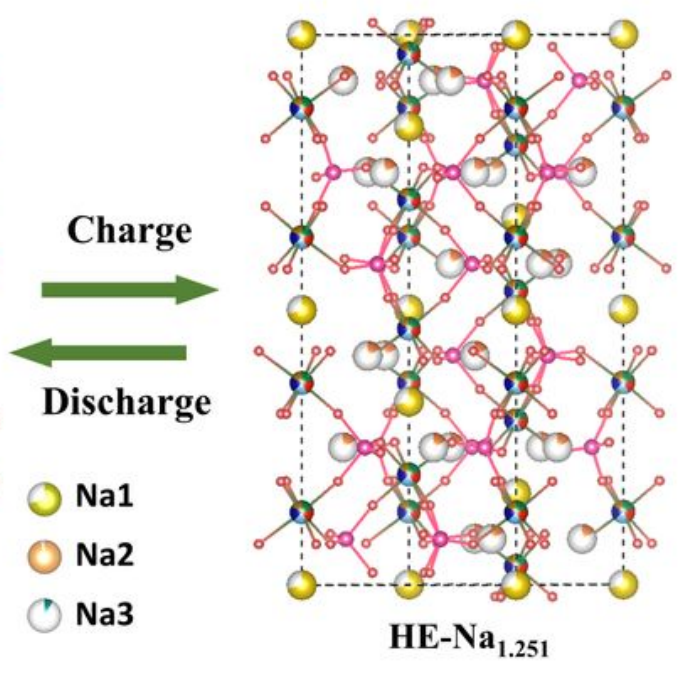

Low
entropy

High entropy

(d)

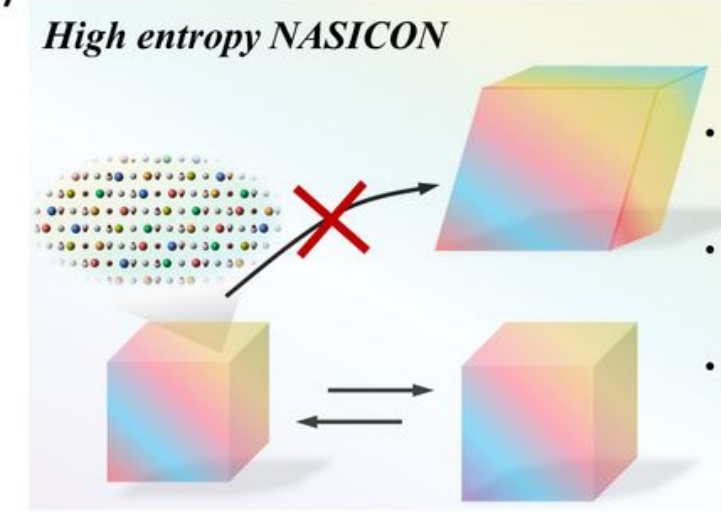

- Suppressed crystal phase transition

- Reduced volume change

- Reversible multisodium storage

Figure 6

Reaction mechanism of the HE-NASICON. (a) Comparison of some typical NASICON materials that reported in terms of volume changes when conducing two-sodium and/or multi-sodium storage 
reactions. ${ }^{11,16,26,38,39,43,45,46,47,48}$ (b) Schematic illustration of the crystal structure evolution of HENASICON during the multi-sodium storage reaction. (c) The elemental mapping images of the HENASICON electrode after 1000 cycles at 5 C. (d) Schematic illustration of the reaction features of the high-entropy NASICON material.
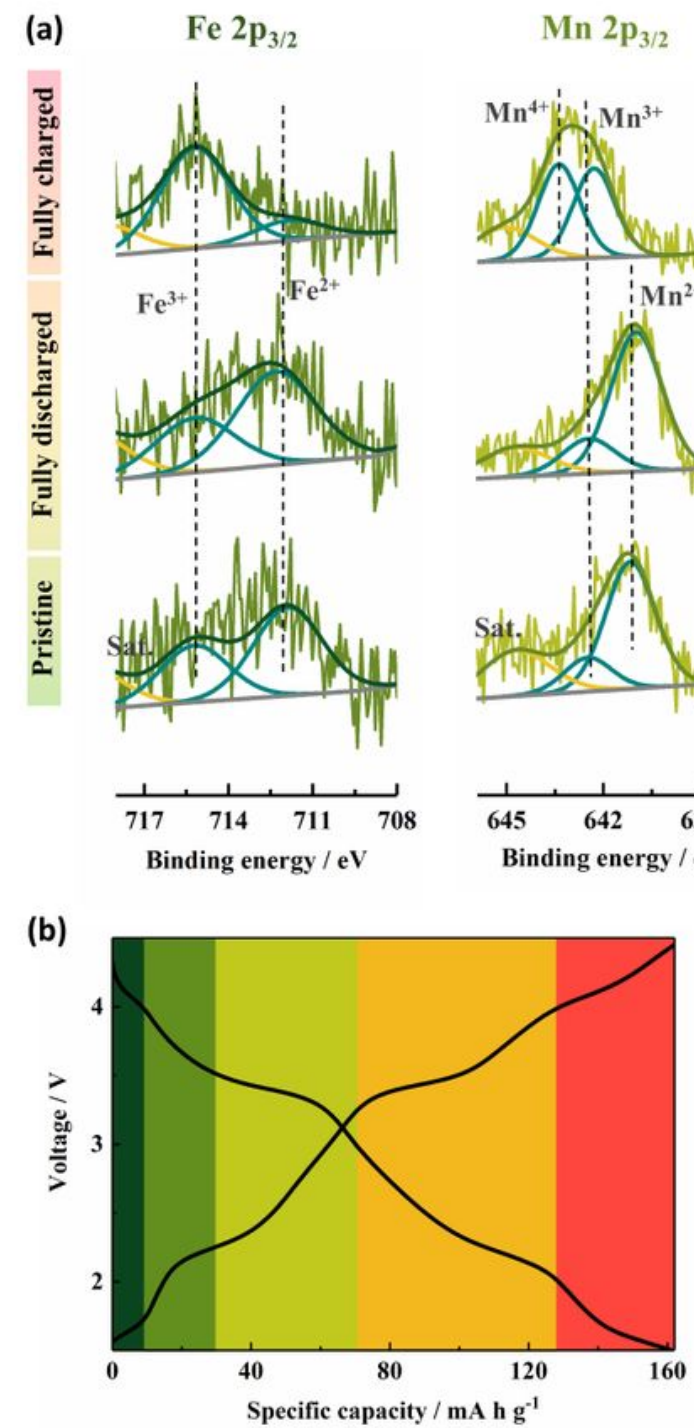

(d)

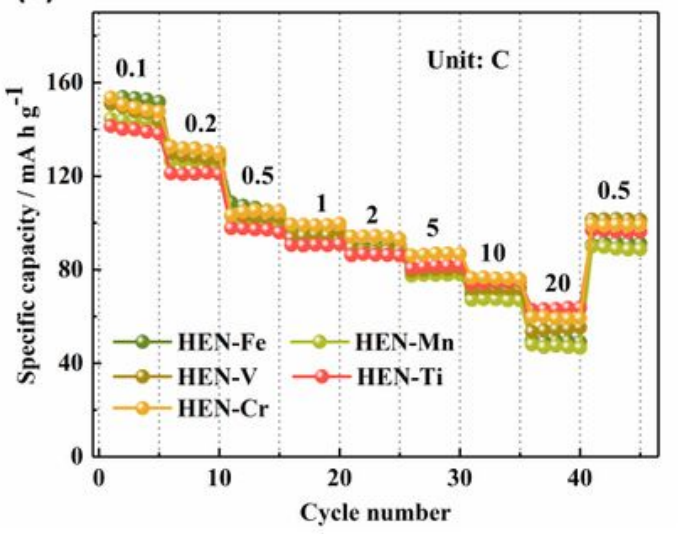

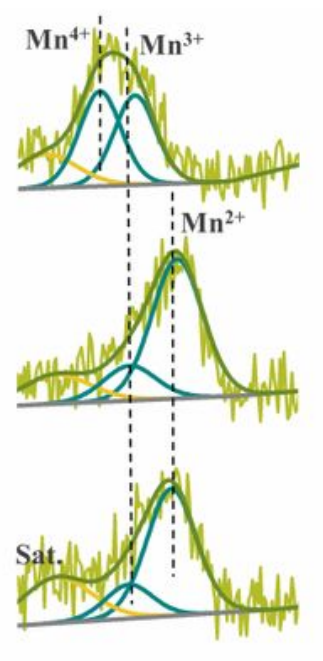
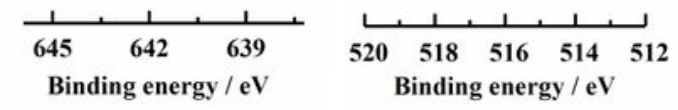

$\mathrm{V} 2 \mathrm{p}_{3 / 2}$

$\operatorname{Ti} 2 \mathrm{p}_{3 / 2}$
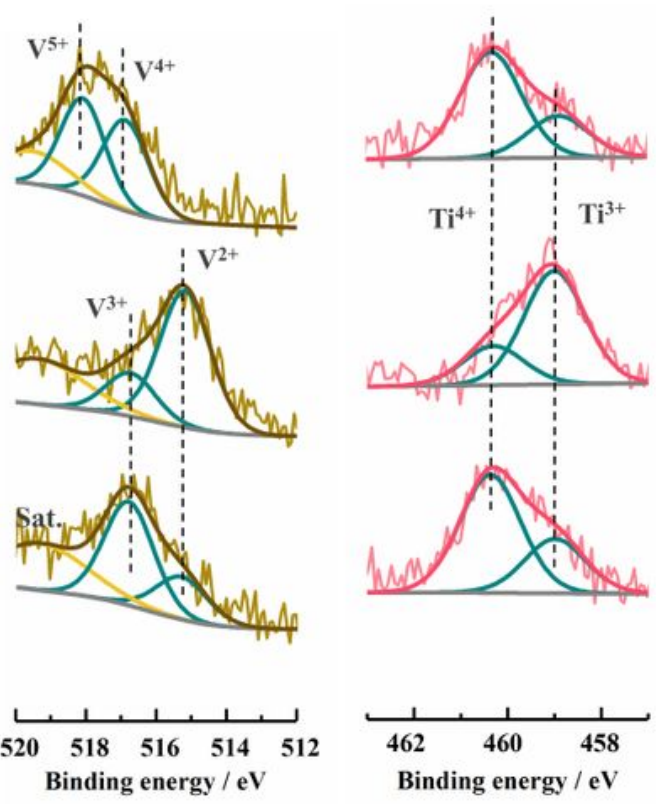

$\operatorname{Cr} 2 \mathrm{p}_{3 / 2}$
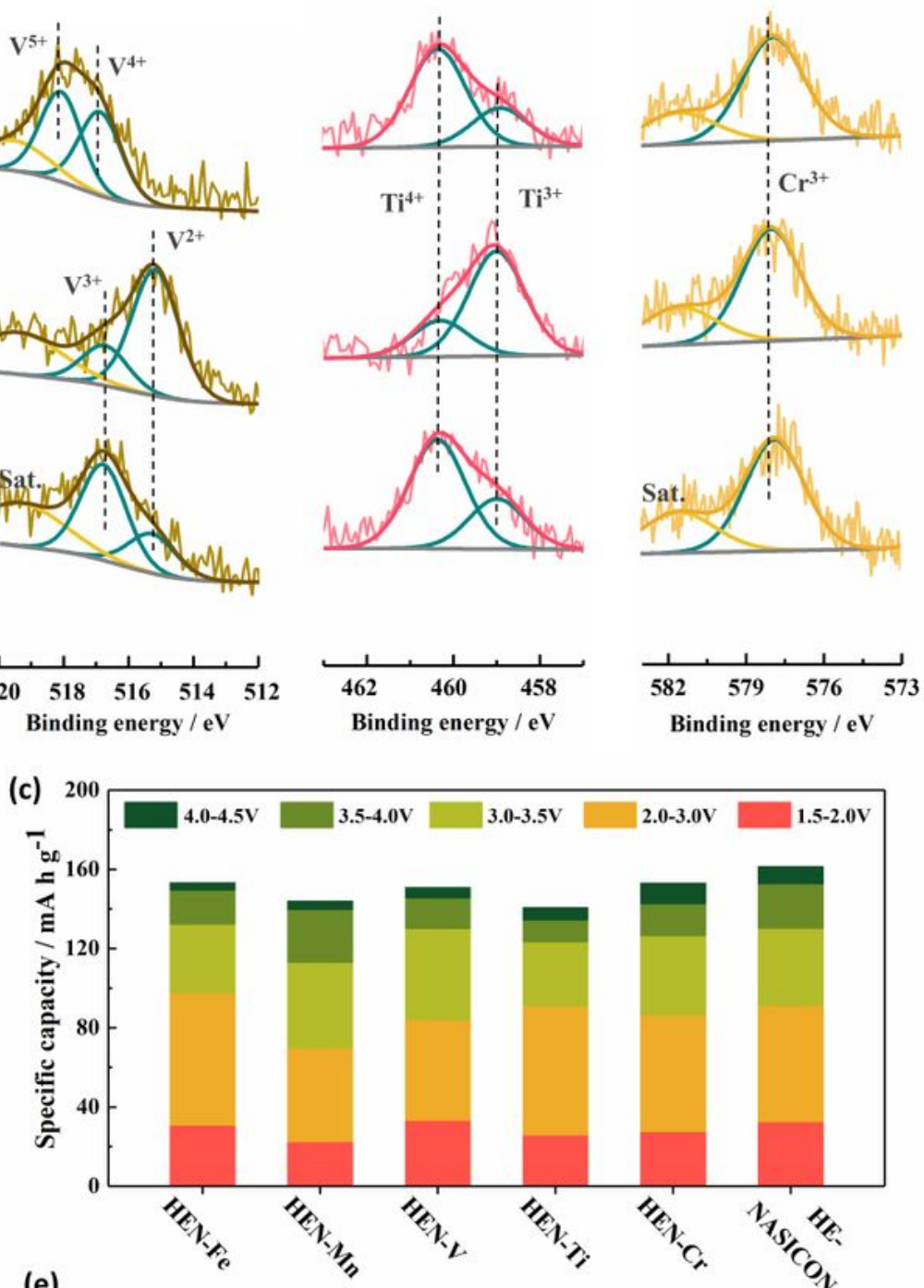

(e)

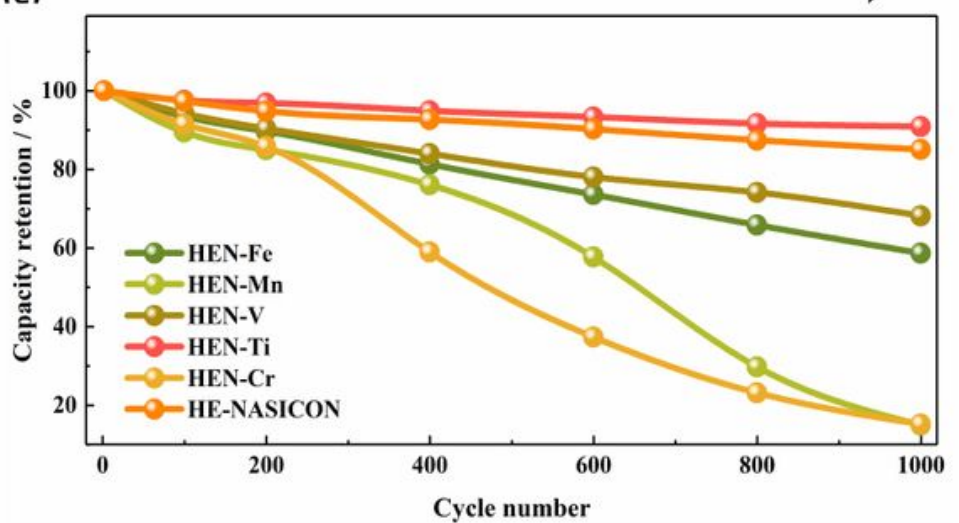

Figure 7 
Impact of the various transition-metals. (a) XPS of the Fe 2p $p_{3 / 2}, \mathrm{Mn} 2 \mathrm{p}_{3 / 2}, \mathrm{~V} 2 \mathrm{p}_{3 / 2}, \mathrm{Ti} 2 \mathrm{p}_{3 / 2}, \mathrm{Cr} 2 \mathrm{p}_{3 / 2}$ that collected from the pristine electrode, fully discharged electrode $(1.5 \mathrm{~V})$, and fully charged electrode (4.5 V) of HE-NASICON. (b) Demonstration of the colors highlighted capacity contribution of voltage regions of $1.5 \sim 2.0 \mathrm{~V}$ (dark green), $2.0 \sim 3.0 \mathrm{~V}$ (green), $3.0 \sim 3.5 \mathrm{~V}$ (light green), $3.5 \sim 4.0 \mathrm{~V}$ (yellow) and $4.0 \sim 4.5 \mathrm{~V}$ (red) in HE-NASICON. (c) Capacity contribution of the various high-entropy NASICON materials at $0.1 \mathrm{C}$. (d) Rate performance and (e) cycling stability of the high- entropy NASICON materials at $5 \mathrm{C}$.

\section{Supplementary Files}

This is a list of supplementary files associated with this preprint. Click to download.

- SupplementaryMaterial.docx 